\title{
Os Critérios Competitivos da Produção: um Estudo Exploratório na Construção de Edificações
}

\author{
José de Paula Barros Neto \\ Jaime Evaldo Fensterseifer \\ Carlos Torres Formoso
}

\section{Resumo}

Prioridades competitivas são objetivos que a empresa deve buscar mais fortemente com o intuito de aumentar a sua competitividade e, por conseguinte, a sua participação no mercado e a sua lucratividade. As principais prioridades competitivas existentes na literatura são: custo, qualidade, desempenho na entrega, flexibilidade, inovatividade e serviços. Cada uma dessas prioridades tem os seus respectivos desdobramentos, pois as suas definições são genéricas e abrangentes. Porém, em virtude das características do setor de construção de edificações, é necessária uma adequação destes conceitos. Assim o objetivo deste artigo é analisar o conteúdo das prioridades competitivas na construção de edificações, levando em consideração as peculiaridades deste setor produtivo. Vale salientar que as prioridades competitivas foram analisadas e desenvolvidas a partir de entrevistas semi-estruturadas realizadas com especialistas na área de gerenciamento da construção e da aplicação dos conceitos em pequenas empresas de construção de edificações do Rio Grande do Sul.

Palavras-chaves: estratégia de produção; construção civil; pequenas empresas.

\begin{abstract}
Competitive priorities are objectives that companies should strongly strive to achieve to increase its competitiveness and, consequently, its market share. Based on the literature, the most important competitive priorities are: cost, quality, time, flexibility, innovativeness and services. Each one of them has its own aspects, because their concepts are vast and generic. But, due to the characteristics of the building industrial sector, it is necessary to make an adaptation of these concepts. Then, the objective of this paper is to analyze the contents of competitive priorities in the building industry, considering the peculiarities of this sector. This study was developed through semi-structured interviews with experts in construction management, application of a strategic production diagnosis and observation of these concepts of competitive priorities in small firms of building industry in Rio Grande do Sul, Brazil.
\end{abstract}

Key words: production strategy; building industry; small firms. 


\section{INTRODUÇÃo}

Definem-se prioridades competitivas como sendo um conjunto consistente de critérios que a empresa tem de valorizar para competir no mercado. Ou seja, em função das competências internas da empresa, do tipo de mercado que ela quer atuar, do grau de concorrência deste mercado e do tipo de produto que ela produz, a empresa terá de escolher entre algumas prioridades competitivas, aproveitando, de tal forma, os seus recursos, capacidades e oportunidades de mercado com o intuito de se tornar competitiva. Observa-se, então, que dependendo dos recursos humanos, físicos e tecnológicos e da observação das necessidades dos clientes e desempenho dos concorrentes da empresa, deve-se definir os critérios competitivos mais adequados e estruturar a função produção, da melhor maneira possível, para que ela seja capaz de dar suporte a esta escolha.

Durante muito tempo a prioridade competitiva da função produção foi a busca incessante da eficiência. Porém, atualmente, verifica-se que esta não é mais a única prioridade do setor e que, dependendo do mercado e dos desejos dos clientes, outras poderão ser mais valorizadas que a busca da redução dos custos (aumento da eficiência). Entre estas prioridades, pode-se citar a qualidade, o prazo, a flexibilidade, a inovação e os serviços.

Deste modo, este artigo pretende desenvolver e explicar as novas prioridades competitivas adequadas à construção de edificações. Elas foram desenvolvidas a partir de entrevistas com especialistas na área de gerenciamento da construção e de um diagnóstico estratégico da função produção de três pequenas empresas de construção de edificações do Rio Grande do Sul.

No início deste trabalho, é apresentada breve revisão bibliográfica sobre estratégia de produção com ênfase nas prioridades competitivas. Na continuação, há a exposição do método de pesquisa e, por fim, apresenta-se a proposta das novas prioridades competitivas adequadas à construção de edificações com suas respectivas justificativas.

\section{Conceituação de Estratégia de Produção}

Wheelwright (1984) e Slack (1993) procuram mostrar, em seus textos, a existência de uma ligação entre a visão de negócio e a visão operacional das empre- 
sas, ressaltando, assim, a importância que deve ser dada à função produção como fonte de vantagem competitiva. Diante do exposto, considera-se, neste estudo, a estratégia de produção como sendo um padrão de decisões referentes à função produção, que devem ser tanto coerentes com a estratégia competitiva da empresa quanto com as decisões relacionadas com as outras funções administrativas (marketing, recursos humanos, setor financeiro etc.).

Com esta abordagem estratégica da produção busca-se introduzir a visão de competitividade dentro do setor de produção ou a incorporação do conceito de eficácia juntamente com o conceito de eficiência (Cardoso, 1997). Com isso, introduz-se maior preocupação com o conhecimento dos clientes, dos concorrentes e do mercado dentro do processo de tomada de decisão referente à função produção. Como conseqüência, nem sempre a busca da eficiência máxima (redução de custos) vai ser o principal objetivo competitivo da produção, pois pode haver outro objetivo que se ajuste melhor com a estratégia competitiva da empresa.

Teoricamente, o estudo de estratégia de produção se divide em dois grandes grupos: conteúdo da estratégia e processo de formulação. O primeiro está focado no que vai ser decidido, enquanto o segundo está interessado em como tais decisões serão obtidas dentro das organizações. Especificamente para este trabalho, serão abordados apenas os assuntos referentes ao conteúdo da estratégia de produção relacionados com os critérios competitivos.

\section{Método de Pesquisa}

Neste trabalho, utilizou-se como estratégia de pesquisa o confronto das opiniões de especialistas com a realidade das pequenas empresas de construção de edificações, na busca de uma síntese sobre os critérios competitivos referentes à função produção deste setor industrial. Para isso, realizaram-se entrevistas com professores, pesquisadores e consultores ligados ao estudo do sistema de produção da construção de edificações, e um diagnóstico estratégico da função produção de empresas deste setor, objetivando analisar as coerências e incoerências na tomada de decisão referente a esta função.

O referido trabalho apresenta algumas limitações: a impossibilidade de generalização dos resultados, em virtude do pequeno número de casos e de os estudos serem restritos a empresas do Rio Grande do Sul; as análises baseadas apenas na visão e opinião dos membros da cúpula das empresas; o estudo relacionado exclusivamente com empresas do subsetor de edificações e as informações ba- 
seadas praticamente em dados qualitativos, devido ao tamanho e às características das empresas pesquisadas.

\section{Processo de Entrevistas}

O tipo de entrevista utilizado foi a semi-estruturada, pois se seguiu um roteiro de perguntas que não era muito rígido, dando assim liberdade ao entrevistador para aprofundar questionamentos ou fazer novas perguntas, de acordo com o andamento da entrevista.

Estas entrevistas foram realizadas com especialistas na área de construção de edificações que atuam no campo da administração da produção e com conhecimentos sobre estratégia. A partir destas condições, foram listados vários nomes e por conveniência escolheram-se nove entrevistados: um professor da UFSC, um pesquisador e consultor do PPGEP/UFRGS, um professor do NORIE/UFRGS, dois consultores de São Paulo, um professor da UFSCar, dois professores da POLI/USP e um professor da UPF/RS. Como este estudo tinha o caráter exploratório e não havia a intenção de generalização dos resultados, escolheu-se uma quantidade de entrevistados que se ajustassem ao perfil já mencionado, ao tempo de cada entrevistado e aos recursos financeiros disponíveis.

As entrevistas realizadas com os três primeiros da lista serviram de teste-piloto para análise do conteúdo das perguntas, do entendimento delas por parte dos entrevistados, do tempo dispendido nas entrevistas e de alguns problemas eventuais que poderiam existir nos questionários. Este teste-piloto ocorreu um mês antes do início do conjunto de entrevistas, com as suas transcrições e análises das respostas sendo feitas imediatamente após o término de cada entrevista. Tudo foi feito com o intuito de aprimorar os questionários para as entrevistas seguintes. É interessante frisar que as informações obtidas nas entrevistas do teste-piloto também foram utilizadas, juntamente com o restante das entrevistas, no processo de análise do setor de construção de edificações.

Segundo Triviños (1987), as entrevistas devem ser transcritas logo após tenham sido realizadas; mas em função do tempo de cada transcrição e da concentração das entrevistas, após o teste-piloto, em uma semana, optou-se por escutar as fitas logo após cada entrevista e analisar quais os pontos falhos, principalmente no que dissessem respeito ao entendimento das perguntas por parte dos entrevistados.

Dividiram-se as entrevistas em três partes. A primeira buscou conhecer questões a respeito do processo de formulação de estratégias, tanto competitivas quanto de produção, no âmbito da construção de edificações. A segunda traba- 
lhou com os critérios competitivos da função produção e as relações com o setor em estudo. Por fim, houve os questionamentos a respeito das categorias de decisão da produção e a construção de edificações. A duração de cada entrevista foi de duas horas, como já era previsto.

A análise de dados, neste tipo de pesquisa, depende muito da interpretação do pesquisador, do seu estilo de pensamento, da apresentação suficiente de evidências e de considerações cuidadosas de interpretações alternativas (Yin, 1994). Deste modo, tentando diminuir a subjetividade e facilitando a análise dos dados, as entrevistas foram analisadas por meio da construção de uma unordered metamatrix (Miles e Huberman, 1984). Esta matriz tem a função de agrupar os dados por questionamento e por entrevistado e facilitar a sua análise. No caso em estudo, as matrizes foram montadas para cada categoria de decisão.

Para trabalhar com este tipo de matriz, é preciso seguir alguns passos: primeiro, montar a tabela com o nome dos entrevistados nas linhas e as perguntas nas colunas. Depois entrar com as respostas de cada entrevistado para cada pergunta e, por fim, fazer a análise dos dados. Esta é feita por meio da busca de palavras que se repetem, de jargões, de modelos recorrentes etc. Mais especificamente, a análise dos dados das entrevistas desta pesquisa foi feita por meio de comparações entre as opiniões dos vários respondentes relativas a cada pergunta, verificando a existência de palavras recorrentes, de afirmações razoáveis e plausíveis que podiam se complementar ou ter significados parecidos.

\section{Diagnóstico Estratégico da Produção}

A realização do diagnóstico estratégico da produção permitiu conhecer o processo de tomada de decisão da função produção das empresas, verificando, entre outras coisas, como elas decidiam investir, o que levavam em consideração neste processo, como agrupavam os vários questionamentos existentes.

Na realização deste diagnóstico foram utilizadas algumas fontes de evidências, tais como:

. entrevistas com pessoas tanto ligadas à função produção quanto a outras funções (compras, recursos humanos, finanças etc.). Elas foram conduzidas pelo pesquisador, que seguiu um roteiro adaptado a cada entrevistado, levando em consideração o seu grau de autonomia dentro da empresa, a sua função na organização e a sua experiência profissional;

. visitas às obras e ao escritório da empresa para verificar in loco os procedimentos de trabalho da empresa; 
. análise documental de formulários, contratos, cadastro de fornecedores e acervo de obras, além da obtenção de informações e dados específicos sobre os empreendimentos, os empreiteiros e os fornecedores.

Trabalhou-se com três pequenas empresas de construção de edificações do Rio Grande do Sul. Procurou-se analisar, cada uma delas, de forma abrangente, apesar de ter sido dada maior ênfase à função produção. Isto possibilitou melhor entendimento delas.

Além dos procedimentos de coleta de dados apresentados acima, foi aplicado um questionário (com escala Likert de cinco pontos, variando do menos importante para o mais importante) em cada empresa, no qual os participantes do processo foram argüidos sobre os critérios competitivos (preço/custo, qualidade, flexibilidade e prazo) que os clientes, de cada nicho de mercado da empresa, mais valorizavam no momento da compra. A análise da função produção foi feita em relação aos critérios mais valorizados.

Vale ressaltar que o mais interessante seria fazer estes questionamentos diretamente aos clientes; porém há algumas dificuldades: o grande número de clientes em potencial interessados em comprar imóveis que não têm conhecimento total sobre o fragmentado mercado da construção; o custo e o tempo necessários para se obter estas informações detalhadas. Além disso, alguns autores, como Slack (1994), defendem que os diretores das empresas têm condição de conhecer os anseios e necessidades de seus clientes.

\section{Estudo de Caso}

Após a elaboração do diagnóstico estratégico, iniciou-se a fase de estudos de casos para submeter os critérios previamente definidos ao entendimento das empresas e, com isso, ajustá-los e validá-los, juntamente com o estudo do processo de formulação, que culminou com a apresentação de um modelo de formulação para pequenas empresas de construção habitacional (Barros Neto, 1999).

A análise dos dados foi feita em duas etapas. A primeira foi uma análise isolada de cada um dos casos (within-case analysis), na qual se fez um estudo de cada um deles com o objetivo de organizar a grande quantidade de dados existentes. O objetivo principal desta primeira fase foi familiarizar-se detalhadamente com os casos em estudo.

A segunda etapa foi uma continuação da primeira, na qual se comparou os vários casos entre si, buscando similaridades e diferenças entre eles que facilitassem a obtenção de conclusões a respeito do objeto em estudo (cross-case analysis). 
Os estudos de caso foram realizados em três pequenas empresas de construção habitacional do Rio Grande do Sul que participaram do diagnóstico estratégico, com o objetivo de validar o processo de elaboração do modelo de formulação proposto e, por conseguinte, os critérios competitivos e suas dimensões utilizadas no referido setor industrial. Procurou-se analisar cada uma delas de forma abrangente, apesar de ter sido dada maior ênfase à função produção. Isto possibilitou melhor entendimento sobre elas, aumentando também os conhecimentos do pesquisador sobre o funcionamento de cada uma delas.

\section{Conteúdo da Estratégia de Produção e Critérios Competitivos}

Os principais elementos que definem o conteúdo de uma estratégia de produção são os critérios competitivos relacionados com a estratégia competitiva da empresa e as categorias de decisão de longo prazo que influenciam a tomada de decisão na função produção das empresas.

A partir da Figura 1, observa-se que o estabelecimento da estratégia de produção pelas empresas inicia-se pela definição de suas estratégias competitivas de acordo com o mercado em que atuam. Após estas definições, parte-se para a determinação dos critérios competitivos, que devem ser priorizados pela função produção de acordo com os aspectos estratégicos definidos na estratégia competitiva. Por fim, desenvolve-se a fase de tomada de decisão, na qual se busca definir como esta função dará suporte aos critérios competitivos escolhidos.

Vale salientar que um dos pontos importantes para a efetivação da estratégia empresarial é a coerência interna e externa da tomada de decisão. A primeira ocorre de duas maneiras: entre as categorias de decisão da produção entre si (coerência horizontal) e entre elas e os critérios competitivos da produção escolhidos (coerência vertical). Já a coerência externa ocorre entre os critérios competitivos e a estratégia competitiva da unidade de negócios (Wheelwright, 1984).

Antes de entrar na discussão dos critérios competitivos, é importante ressaltar que eles podem ser classificados em dois tipos: os critérios qualificadores, aqueles que devem estar num patamar mínimo exigido pelo mercado, ou seja, para um produto competir no mercado, ele deve satisfazer um padrão mínimo de desempenho; e os critérios ganhadores de pedido, aqueles que devem oferecer desempenho melhor do que o da concorrência para que aumentem a competitividade da empresa e ganhem mercado da concorrência (Hill, 1995). Vale enfatizar que 
a seleção entre critérios qualificadores e ganhadores de pedido dependerá das circunstâncias de cada mercado no qual a empresa atua.

\section{Figura 1: Conteúdo de uma Estratégia de Produção}

\section{ESTRATÉGIA COMPETITIVA}

ESTRATÉGIA DE PRODUÇÃO

\begin{tabular}{|l|}
\hline CRITÉRIOS COMPETITIVOS \\
\hline . Custo \\
. Qualidade \\
. Flexibilidade \\
. Desempenho na entrega \\
\hline
\end{tabular}

\begin{tabular}{|l|l|}
\hline CATEGORIAS DE DECISÃO \\
\hline Estruturais & Infra-estruturais \\
\hline Instalações & . Organização \\
. Capacidade & . Força de trabalho \\
. Tecnologia & . Gerência da qualidade \\
. Integração vertical & Relação com fornecedores \\
& . Planejamento e controle da \\
& produção \\
\hline
\end{tabular}

Fonte: Pires (1995).

A partir destes conceitos, confirma-se o que já foi exposto sobre a priorização dos critérios competitivos e reforça-se a necessidade de as empresas se concentrarem no que realmente interessa para o cliente. No entanto é importante lembrar também que os critérios competitivos precisam ter um patamar mínimo de desempenho; caso contrário eles podem comprometer o desempenho competitivo dos outros critérios.

No início do trabalho, utilizaram-se os critérios clássicos: custo, desempenho na entrega, flexibilidade, qualidade (vide Figura 1), tentando usá-los nas pequenas empresas de construção de edificações. Porém, em virtude das características deste setor industrial, de sua função produção e do porte das empresas estudadas, observou-se que eles precisariam ser mais bem detalhados e adaptados. Deste modo, chegou-se ao Quadro 1, o qual relaciona os desejos dos clientes e os critérios competitivos da produção, tendo o objetivo de apresentar os fatores genéricos que os clientes reconhecem e valorizam e, com isso, facilitar a sua organização e desdobramento em critérios competitivos e suas dimensões para a função produção das pequenas empresas de construção de edificações. 


\section{Quadro 1: Relação dos Desejos dos Clientes com os Critérios Competitivos da Função Produção das Empresas de Construção de Edificações}

\begin{tabular}{|c|c|}
\hline DESEJOS DOS CLIENTES & $\begin{array}{c}\text { CRITÉRIOS COMPETITIVOS DA } \\
\text { PRODUÇÃO }\end{array}$ \\
\hline $\begin{array}{l}\text { PREÇO } \\
\text { Menor preço } \\
\text { Condições de pagamento }\end{array}$ & $\begin{array}{l}\text { CUSTO } \\
\text { Menor custo (aumento da } \\
\text { produtividade) } \\
\text { Adequacão ao fluxo de caixa }\end{array}$ \\
\hline $\begin{array}{l}\text { PRAZO } \\
\text { Prazo de entrega } \\
\text { Garantia de entrega no prazo }\end{array}$ & $\begin{array}{l}\text { DESEMPENHO NA ENTREGA } \\
\text { Velocidade de produção } \\
\text { Confiabilidade de entrega } \\
\end{array}$ \\
\hline $\begin{array}{l}\text { PRODUTO } \\
\text { Desempenho do produto } \\
\text { Possibilidade de alterações } \\
\text { Introdução de novos produtos }\end{array}$ & $\begin{array}{l}\text { QUALIDADE } \\
\text { Conformação com os contratos } \\
\text { Conformação com os projetos } \\
\text { Qualidade do processo (boa execução) } \\
\text { FLEXIBILIDADE } \\
\text { Flexibilidade do produto } \\
\text { INOVAÇÃO }\end{array}$ \\
\hline $\begin{array}{l}\text { SERVIÇOS ASSOCIADOS } \\
\text { Durante a construção } \\
\text { Após a construção }\end{array}$ & $\begin{array}{l}\text { SERVIÇOS } \\
\text { Atendimento } \\
\text { Assistência técnica }\end{array}$ \\
\hline
\end{tabular}

\section{Custo}

Em função de o produto da construção ser de elevado valor, o preço tem importância muito grande durante o processo de tomada de decisão do cliente. Além disso, as condições de pagamento também podem ter influência considerável, pois, muitas vezes, o valor da prestação e a forma de pagamento preponderam em relação ao preço real do imóvel.

A produção tem papel fundamental na competição pelo menor preço por meio da atuação nos custos de produção. Esta atuação se dá por meio da busca de menores custos e de melhor adequação ao fluxo de caixa dos empreendimentos.

É notória a inclusão do custo como um critério competitivo da produção. Este, por sua vez, está diretamente ligado à eficiência da empresa em produzir mais utilizando menos recursos, ou seja, sendo mais produtiva. De acordo com as entrevistas com especialistas, este é o critério mais perseguido pelas empresas na construção de edificações. Porém, muitas vezes, as empresas não sabem muito claramente como reduzir estrategicamente os seus custos.

Além disso, a função produção da empresa pode ajustar-se às condições de pagamento do financiamento do empreendimento por meio de um bom planeja- 
mento e seqüenciamento das atividades, procurando adaptar-se aos desembolsos previstos. Ela também pode investir em processos construtivos e equipamentos que possibilitem a execução postergada de atividades, sendo elas executadas mais próximo do término da obra. Com isso, ela se capitalizará no início e concentrará as despesas no final do empreendimento, obtendo maior retorno financeiro.

\section{Desempenho na Entrega}

Segundo Slack (1993) pode-se dividir o critério desempenho na entrega em velocidade de produção (ou entrega) e confiabilidade de entrega, corroborando Pires (1995). Este critério está baseado na valorização do tempo.

A velocidade de produção caracteriza-se pela capacidade de uma empresa fazer determinada atividade mais rápido que a concorrência. Para a construção de edificações, este critério é valorizado em nichos de mercado onde os empreendimentos precisam de um retorno rápido do investimento. Normalmente são obras comerciais (shopping centers, hotéis, hospitais etc.). Nas obras residenciais, ele não é tão valorizado, porque os compradores freqüentemente não têm condições financeiras para suportar a aceleração do ritmo de produção. Exceções à regra são os empreendimentos financiados por investidores.

A confiabilidade de entrega é a capacidade da empresa de entregar o produto no prazo prometido (Slack, 1993). Normalmente este critério está diretamente atrelado com a definição do tempo de entrega (velocidade de entrega). Além disso, o reconhecimento de uma empresa como tendo um prazo de entrega confiável, é forjado durante anos.

Em muitas indústrias, este critério já é considerado qualificador; porém na construção de edificações o prazo de entrega é bastante negligenciado pelas empresas, fazendo com que, em muitas situações, a confiabilidade de entrega no prazo seja explorada como critério ganhador de pedido.

Contudo o prazo pode ser uma variável importante no processo de escolha dos clientes da construção de edificações, pois, muitas vezes, os empreendimentos levam um tempo considerável para serem construídos, fazendo com que os clientes desembolsem recursos durante um grande período de tempo, sem, contudo, poderem usufruir o bem.

Deste modo, a atuação no campo de competição prazo pode ocorrer de duas maneiras: na valorização do prazo de entrega, no qual o tempo de entrega é o que interessa e, por conseguinte, a rapidez de produção é priorizada (velocidade de produção); ou na garantia da entrega, na qual a conclusão do empreendimento no 
prazo fixado é o mais importante e, conseqüentemente, a garantia de sua execução dentro do cronograma acordado é fator decisivo (confiabilidade de entrega).

\section{Qualidade}

No início, tentou-se trabalhar com as oito dimensões da qualidade apresentadas por Garvin (1987). Porém, após as entrevistas com os especialistas e os diagnósticos estratégicos das empresas, verificou-se que algumas destas dimensões não se adaptavam muito bem à função produção da construção de edificações, pois elas não poderiam ser obtidas por meio desta função, em virtude de características do setor de construção civil, principalmente aquela que ressalta que muitas destas dimensões são valorizadas durante a fase de projetos, sendo a função produção, na maioria das vezes, apenas mera executora do que foi estabelecido nos projetos. Deste modo, esta função quase não adiciona valor ao produto; mas é capaz de proporcionar perda de valor, caso não cumpra corretamente as determinações dos projetos.

Corroborando com estes argumentos, Picchi (1993) divide a qualidade do produto recebido pelo cliente em três componentes: qualidade de projeto, que se refere ao grau em que o produto, por meio de sua concepção e especificações, atende às necessidades dos clientes; qualidade de conformação, que abrange os aspectos de atendimento às especificações e ao projeto, bem como aspectos de eficiência do processo; e qualidade de serviços, que envolve atendimento e informação ao consumidor, bem como a assistência técnica. A partir desta divisão, observa-se, portanto, que a função produção é responsável diretamente pela qualidade de conformação e de serviços; porém esta última, neste trabalho, é considerada como um critério competitivo e não como uma dimensão competitiva da qualidade e, por conseguinte, será detalhada em outra seção.

Isto posto, verifica-se que o critério competitivo qualidade pode dividir-se em três dimensões competitivas: conformação com os contratos, conformação com os projetos e qualidade no processo construtivo.

\section{Conformação com os Contratos}

A construção de edificações trabalha com muitos materiais e detalhes arquitetônicos e construtivos. Para organizar todo esse processo, há os memoriais descritivos que são definidos e prescritos nos contratos entre empresas e clientes. Estes memoriais têm o objetivo de detalhar as especificações dos materiais a serem utilizados no empreendimento, visando a definir um padrão de qualidade de acordo com os desejos dos clientes. Deste modo, uma forma de obter a qualidade desejada e especificada é mediante o atendimento rigoroso das 
especificações definidas. Por fim, é importante salientar a necessidade de um bom detalhamento destes memoriais para que haja cumprimento adequado dos requisitos de qualidade, por parte da função produção.

\section{Conformação com os Projetos}

Sabe-se que, na construção de edificações, trabalha-se com vários processos construtivos executados por profissionais diferentes e que para muitos destes processos há um projeto detalhado, com o intuito de decifrar os desejos dos clientes e transformá-los em um objeto. Assim uma outra maneira de se obter um produto de boa qualidade e atendendo às necessidades dos clientes é por meio do desenvolvimento de projetos bem detalhados e compatibilizados, permitindo à função produção executar, da melhor maneira possível, o que foi determinado. No entanto é importante ressaltar que a função produção também tem de estar preparada para utilizar bem estes projetos, mediante, por exemplo, o treinamento dos operários.

\section{Qualidade de Execução dos Processos Construtivos}

Muito dos problemas de qualidade do produto são resolvidos por meio do desenvolvimento de bons projetos e de um bom detalhamento das especificações dos materiais. Porém há detalhes nos processos construtivos que fogem tanto do escopo dos projetos, por mais detalhado que eles sejam, quanto das especificações. Por exemplo, os processos de execução de alvenaria, de assentamento de cerâmicas, de colocação de portas e esquadrias têm nuanças e detalhes que somente podem ser observados durante a sua execução. Deste modo, a função produção das empresas deve estar preparada para obter uma boa qualidade de execução de seus processos construtivos. Isto pode ocorrer, por exemplo, mediante o treinamento da mão-de-obra, da utilização de ferramentas adequadas, do desenvolvimento de procedimentos e da racionalização da produção.

\section{Flexibilidade}

O conceito flexibilidade é bastante amplo, o que dificulta a sua operacionalização. Então, antes de discutir este critério na construção de edificações, serão apresentados a seguir alguns tipos de flexibilidade.

- Flexibilidade de produto: facilidade com que a empresa consegue adaptar seus produtos a um grupo restrito de clientes ou a um cliente individualmente.

- Flexibilidade de mix: facilidade com que a empresa altera o que está sendo produzido num dado espaço de tempo, modificando os volumes de produção dos diferentes produtos por ela oferecidos. 
- Flexibilidade de entrega: facilidade com que a empresa altera os prazos de entrega anteriormente pactuados (para mais ou para menos), atendendo solicitação dos seus clientes.

. Flexibilidade de volume de produção: facilidade com que a empresa se adapta às flutuações na demanda de mercado por seus produtos, mudando os totais produzidos.

A definição das dimensões competitivas da flexibilidade partiu dos conceitos e tipos de flexibilidade de sistema (produto, mix, volume e de entrega) descritos e apresentados acima; mas existem peculiaridades que merecem ser discutidas.

Com relação à construção de edificações, a flexibilidade mais evidenciada é a de produto, pois os outros três tipos de flexibilidade de sistema não se ajustam muito à construção de edificações. A flexibilidade de mix é difícil de ser implementada na construção de edificações em virtude do longo tempo de produção e do seu tipo de produto. A flexibilidade de volume, por sua vez, é inerente ao subsetor, pois ele é fortemente baseado na mão-de-obra, que é altamente flexível e bastante sensível às oscilações conjunturais. Por fim, a flexibilidade de entrega confunde-se com a velocidade de produção.

A flexibilidade de produto está ligada à facilidade com que a empresa consegue adaptar seus os produtos a um grupo restrito de clientes ou a um cliente individual. Este tipo de flexibilidade poderá ocorrer na construção de edificações, por exemplo, mediante a oferta de edifícios com vários tipos de apartamentos ou com um apartamento padrão com algumas possibilidades de mudança na sua distribuição interna. Para que isso ocorra, a empresa tem de investir muito em planejamento, em projeto, em padronização dos processos produtivos e na definição das possibilidades de mudanças.

Neste tipo de flexibilidade, questiona-se tanto quais modificações serão permitidas (o tipo de modificação) quanto a extensão da modificação (o quanto se poderá modificar) e também o tempo para solicitar estas modificações (até quando poderão ser feitas solicitações de modificações pelos clientes). Ou seja, define-se a flexibilidade de resposta — período de tempo que a empresa leva para se adaptar, e a flexibilidade de faixa — extensão da mudança (flexibilidade) a qual a empresa consegue se adaptar (Corrêa e Slack, 1994).

Vale ressaltar que, além dos tipos explicitados, existem outros mais específicos citados por vários autores (Gerwin [1993], De Meyer et al. [1989], entre outros); porém foge ao escopo deste trabalho o aprofundamento da discussão sobre o restante dos tipos. 


\section{Inovação}

Do início da revisão bibliográfica até o processo de diagnóstico, observou-se que o critério competitivo inovação era fortemente vinculado a empresas de alta tecnologia e com produtos de vida útil pequena (Brown, 1996), o que representa um contexto bem diferente do existente na construção, principalmente nas pequenas empresas. Em virtude disso, resolveu-se, em um primeiro momento, não considerá-lo como um critério competitivo aplicável a este subsetor.

No entanto percebeu-se em bibliografias específicas da construção de edificações (Barros [1996], entre outras), que a questão da inovação estava sendo abordada, porém dentro de uma perspectiva exclusivamente tecnológica. Contudo, durante as entrevistas com especialistas, alguns dos respondentes mencionaram exemplos de empresas que eram conhecidas no mercado como inovadoras, tanto em produtos quanto em processos. Para finalizar, verificouse que uma das empresas que participou do diagnóstico estratégico da produção valorizava a busca constante de inovações em virtude do perfil empreendedor de um de seus diretores, que estava sempre procurando novidades no mercado. Além disso, durante a análise e discussão do relatório deste diagnóstico, foi mencionado que esta empresa era reconhecida e valorizada no mercado como sendo inovadora.

Diante do exposto acima, considerou-se então a inovação como um critério competitivo da produção na construção de edificações, levando-se em conta também que nos tempos atuais de mudança e valorização do novo, do moderno e da customização, a inovação poderá vir a ser forte fator de decisão para clientes desejosos de produtos inovadores e diferenciados.

Portanto, na construção de edificações, este critério competitivo fica evidente por meio de novas concepções arquitetônicas ou novos materiais de construção (produto) e novas formas de construir (processo). A primeira dimensão segue o mesmo raciocínio das dimensões de qualidade intrínseca e qualidade secundária (Garvin, 1987), no qual a função produção é mera executora do que se determina nos projetos.

No entanto, a inovação não é muito valorizada neste setor industrial, pois ele é formado por empresas pequenas e conservadoras, o que dificulta a introdução e o desenvolvimento dos quatro fatores: a explicitação estreita dos objetivos da inovação (do que se quer inovar); a definição da estrutura organizacional para a mudança (equipes multidisciplinares, por exemplo); a criação da cultura empresarial de valorização da inovação; e a disponibilidade dos recursos (físicos, financeiros), citados por Carvalho Jr. (1997). Atualmente, as poucas empresas que 
valorizam este critério têm forte influência do perfil do executivo-chefe e/ou dono da empresa; porém sem um planejamento deliberado de desenvolvimento e valorização da inovação como um critério competitivo.

\section{Inovação dos Materiais}

Esta dimensão está relacionada com o acompanhamento das inovações oriundas da indústria de materiais de construção e os reflexos delas na escolha dos clientes, pois a função produção deve estar preparada para acompanhar esta evolução, tendo o cuidado de sempre se manter atualizada não só com os produtos, mas também com as suas características de execução. Esta influência maior é dos materiais de acabamento; mas os outros também merecem acompanhamento, pois podem contribuir na diminuição dos desperdícios, aumentos de produtividade etc.

\section{Inovação nos Processos}

Neste caso, observa-se que o objetivo desta dimensão é com a inovação dos processos de execução das várias atividades e operações inerentes à construção de edificações. Deve-se verificar então o grau de interesse dos clientes em novos processos construtivos que proporcionem novas formas arquitetônicas, novos aproveitamentos dos espaços ou status diferenciado. Para isso, a função produção deve estar preparada para introdução de novas tecnologias, trabalhando com um pessoal criativo e motivado, procurando estar sempre atualizada com as inovações que surgem no mercado, fazendo análises comparativas de viabilidade técnico-econômica entre os processos novos e antigos etc.

\section{Serviços}

Ultimamente, a prestação de serviços associados aos produtos vem sendo cada vez mais valorizada como um critério importante (Chase e Garvin, 1989; Contador, 1995; Côrrea e Gianesi, 1996). Segundo Corrêa e Gianesi (1996), em algumas situações, os produtos de empresas concorrentes são muito semelhantes nos seus preços, prazos e desempenho, e assim o que vai acabar diferenciando uma empresa da outra é o seu contato com o cliente e como ela o trata. Corroborando estes autores, Cardoso (1997) também destacou os serviços como uma das estratégias de diferenciação das empresas de construção de edificações.

Além disso, durante as entrevistas com os especialistas, foi ressaltada esta tendência de valorização dos serviços dentro da construção de edificações. Isto também foi observado no diagnóstico estratégico, pois o proprietário e diretor de uma das empresas enfatizou a importância dos serviços para ele e afirmou que todos os esforços são direcionados para o pleno atendimento dos clientes antes, durante e depois da execu- 
ção do empreendimento. Segundo o mesmo diretor, a empresa é conhecida na cidade pelo padrão de qualidade de seus serviços prestados aos clientes.

Após a argumentação acima, deve-se considerar, portanto, a prestação de serviços como um critério competitivo e não mais como uma dimensão competitiva, conforme desejava Garvin (1987).

\section{Atendimento}

Esta dimensão competitiva está diretamente ligada à presteza da empresa, ou seja, à rapidez, à cortesia e à competência no atendimento ao cliente durante a execução do empreendimento. Muitas construtoras, no entanto, não valorizam este item e não se preocupam em fornecer atendimento sistemático durante a construção, tirando dúvidas sobre o processo construtivo, sobre as questões de pagamento de parcelas dos imóveis etc. Porém isto deveria ser feito ostensivamente em virtude de o produto da construção ser caro e de longo prazo, no qual os clientes, na maioria das vezes, começam a pagá-lo muito antes dele ser entregue.

$\mathrm{O}$ atendimento pode ser realizado em reuniões periódicas entre construtores e clientes, nas quais os responsáveis pela produção explicam o andamento da obra e se predispõem a esclarecer as dúvidas. Os operários e engenheiros também podem ser treinados para receber os clientes nas obras, em visitas esporádicas ou periódicas, incentivadas pela empresa.

\section{Assistência Técnica}

Após a conclusão da obra e o início de utilização dos imóveis, eles estão susceptíveis a problemas que precisam ser corrigidos. Estas correções, normalmente, ficam sob a responsabilidade da função produção, que deve agir com rapidez, presteza, cordialidade e responsabilidade.

Vale ressaltar que a assistência técnica tem papel importante dentro da empresa, pois é por meio dela que se verifica o grau de satisfação dos clientes e se observa os prováveis erros existentes, que foram capazes de provocar danos.

Deste modo, um dos pontos fortes para uma boa assistência técnica reside na capacitação da mão-de-obra responsável por ela. Isto é importante porque, em muitas situações, o operário vai trabalhar em ambientes que já vêm sendo ocupados pelos proprietários e, portanto, ele precisa, por exemplo, ser cuidadoso para não danificar os móveis e utensílios existentes nestes ambientes. Além disso, muitas vezes os responsáveis pela assistência técnica devem estar preparados para atender às reclamações de clientes insatisfeitos com o produto da empresa, tentando resolver rapidamente o problema e aproveitando o contato com o clien- 
te para melhorar a imagem da empresa. No entanto o serviço de assistência técnica e manutenção, na maioria das vezes, é feito por uma equipe deslocada da obra, sem nenhum preparo para trabalhar com estes tipos de serviços.

\section{Considerações Finais}

Neste artigo, apresentou-se uma discussão sobre o conteúdo da estratégia de produção, com ênfase nos critérios competitivos, especificando a sua adaptação à construção habitacional. Teve-se como base os conhecimentos a respeito da estratégia de produção e da construção civil, que apresenta peculiaridades que a diferenciam da indústria fabril tradicional. Então, em virtude destas peculiaridades, da sua função produção e das características das pequenas empresas, tornou-se necessário adaptar os conceitos de estratégia de produção para este setor industrial.

Utilizou-se, para isso, um conjunto de entrevistas aliado à um diagnóstico estratégico e à um estudo de caso em três empresas de construção habitacional do Rio Grande do Sul.

Com o exposto no artigo, observa-se a necessidade de fazer uma adaptação, para setores industriais peculiares, de conceitos relacionados ao conteúdo da estratégia de produção, sob pena de comprometer o trabalho de formulação de estratégias de produção, pois os conceitos apresentados genericamente podem não se ajustar à indústria em estudo, dificultando a definição de estratégias claras de produção.

\section{ReferÊnCIAS Bibliográficas}

BARROS, M. M. B.

Metodologia para implantação de tecnologias construtivas racionalizadas na produção de edifícios. São Paulo, 1996. Tese (Doutorado em Engenharia Civil) - Escola Politécnica, Universidade de São Paulo.
BARROS NETO, J. P.

Proposta de um modelo de formulação de estratégia de produção para pequenas empresas de construção habitacional. Porto Alegre, 1999. Tese (Doutorado em Administração) - Programa de PósGraduação em Administração, Universidade Federal do Rio Grande do Sul. 
BROWN, S.

\section{Strategic manufacturing for} competitive advantage: transforming operations from shop floor to strategy. Englewood Cliffs, NJ: Prentice-Hall, 1996.

\section{CARDOSO, F. F.}

Estratégias empresariais e novas formas de racionalização da produção no setor de edificações no Brasil e na França - Parte 2: do estratégico ao tático. Estudos Econômicos da Construção, v. 2, n. 3, p. 119-160, 1997.

\section{CARVALHO JR., J. M.}

Estratégias de produção: a manufatura como arma competitiva, um estudo de caso. Porto Alegre, 1997. Dissertação (Mestrado em Administração) - Programa de Pós-Graduação em Administração, Universidade Federal do Rio Grande do Sul.

CHASE, R. B.;

GARVIN, D. A.

The service factory. Harvard Business Review, p. 61-69, 1989.

CONTADOR, J. C.

Campos da competição. Revista de Administração, v. 30, n.1, 1995.

CORRÊA, H. L.;

GIANESI, I. G. N.

Administração estratégica de serviços. São Paulo: Atlas, 1996.
CORRÊA, H.;

SLACK, N.

Flexibilidade estratégica na manufatura: incertezas e variabilidade de saídas. Revista de Administração, v. 29. n.1, 1994.

DE MEYER, A.

The manufacturing contribution to innovation. Research and the development of pedagogical materials, [S.n., s.l.], 19-. working paper n. 90.

GARVIN, D.

Competing on the eight dimensions of quality. Harvard Business Review, 1987.

GERWIN, D.

Manufacturing flexibility: a strategic perspective. Management Science, v. 39, n. 4, Apr. 1993.

HILL, T.

Manufacturing strategy: text and cases. London: MacMillan Business, 1995.

MILES, B. M.;

HUBERMAN, A. M.

Qualitative data analysis: a sourcebook of new methods. London: Sage Publications, 1984. 
PICCHI, F. A.

Sistemas de qualidade: uso em empresas de construção. São Paulo, 1993. Tese (Doutorado em Engenharia Civil) - Escola Politécnica, Universidade de São Paulo.

PIRES, S.

Gestão estratégica da produção. Piracicaba: Unimep, 1995.

SLACK, N.

Vantagem competitiva em manufatura: atingindo competitividade nas operações industriais. São Paulo: Atlas, 1993.
TRIVIÑOS, A. N. S.

Introdução à pesquisa em ciências sociais: a pesquisa qualitativa em educação. São Paulo: Atlas, 1987.

WHEELWRIGHT, S.

Manufacturing strategy: defining the missing link. Strategic Management Journal, v. 5, 1984.

YIN, R.

Case study research: design and methods. 2. ed. London: Sage Publications, 1994. 